\title{
A Meta-synthesis on the Effects of Combining Heart Rate Variability Biofeedback and Positive Emotion on Workplace Performance
}

\author{
Hilda Barrett ${ }^{1} \&$ Nash Popovic ${ }^{2}$ \\ ${ }^{1}$ Three Poplars, Tuesley Lane, Godalming, Surrey, GU7 1SJ, United Kingdom. \\ ${ }^{2}$ University of East London, Stratford Campus, Water Lane, London, E15 4LZ. \\ Correspondence: Hilda Barrett, Three Poplars, Tuesley Lane, Godalming, Surrey, GU7 1SJ, United Kingdom. E-mail: \\ hilda@insighttothrive.com
}

Received: June 24, 2015

doi:10.11114/ijsss.v3i5.964
Accepted: July 9, 2015

Available online: July 22, 2015

URL: http://dx.doi.org/10.11114/ijsss.v3i5.964

\begin{abstract}
Heart Rate Variability (HRV) can be used to measure vagal tone which provides insight into the flexibility of the autonomic nervous system (ANS). A flexible ANS is optimal for both physical and psychological well-being. This study is a meta-synthesis of research to-date, using a systematic review methodology, on self-regulation interventions in the workplace that are based on a combination of HRV bio-feedback and the self-generation of positive emotion. The effects of these workplace self-regulation interventions are physiological, psychological and organisational. At the physiological level they can have a beneficial impact on the following factors: blood pressure, cholesterol, glucose, DHEA, cortisol and HRV. At a psychological level they decrease negative affect and increase positive affect. They impacted organisational performance through improvement in: organizational quality, cognitive performance, ability to manage stressful transitions and reduced costs.
\end{abstract}

Keywords: Heart rate variability; biofeedback; positive emotions; stress; resonant breathing; psychological well-being; workplace performance

\section{Introduction}

\subsection{Positive Affect}

There is a growing body of evidence suggesting the link between positive affect and physical health. In their meta-analysis of 39 articles of positive wellbeing and mortality, Childa and Steptoe (2008), highlighted that positive affect was linked to reduce mortality. Research by Kubzansky and Thurston (2007) found those with higher wellbeing traits had a significantly reduced risk of coronary heart disease. Ostir, Markides, Peek \& Goodwin (2001) reported that there was a lower incidence of stroke for those who had higher positive affect.

\section{$1.2 \mathrm{HRV}$}

HRV is a measure of the variance between heart beats. Because it gives a picture of the functioning of the ANS it is "a physiological correlate of physical and psychological health" (Burg \& Wolf, 2012, p. 135). High HRV is indicative of a healthy ANS that responds quickly and effectively to changing demands. It is associated with many indices of psychological well-being, including self-regulation (Segerstrom \& Nes, 2007) tonic positive emotionality (Oveis et al., 2009), pro-social behaviour (Eisenberg, Carlo \& Murphy, 1995), decreased maladaptive coping (El-Sheikh \& Harger, 2001), being more cheerful and dealing well with stress (Porges, 1994). By contrast, decreased variability is associated with poor health status, and chronic arousal exhausts the ANS results in a predisposition to illness, poor self-regulation and raised premature mortality risk (Dekker et al, 1997).

Positive psychology research indicates that positive emotions increase our personal resources and undo some of the impact of negative emotions (Fredrickson, 1998; Fredrickson et al., 2000). Fredrickson has expanded this research further and published in 2013 the link between positive emotion and increased vagal tone, as measured by HRV (Kok et al., 2013).

Using biofeedback, the activity of the ANS can be electronically monitored and presented as wave forms in real time. This can help the user to train to build their voluntary control to deliberately alter their HRV patterns. HRV has been shown to co-vary with emotion (McCraty, Atkinson, Tiller, Rein \& Watkins, 1995), for example, negative emotions like 
anger, shift the balance towards a sympathetic nervous system (SNS) pre-eminence which is represented by a jagged wave form in the HRV reading. In contrast, positive emotions, such as appreciation, result in parasympathetic nervous system dominance (PSNS) and a smooth sign wave reading, which indicates coherence (see figure 1).
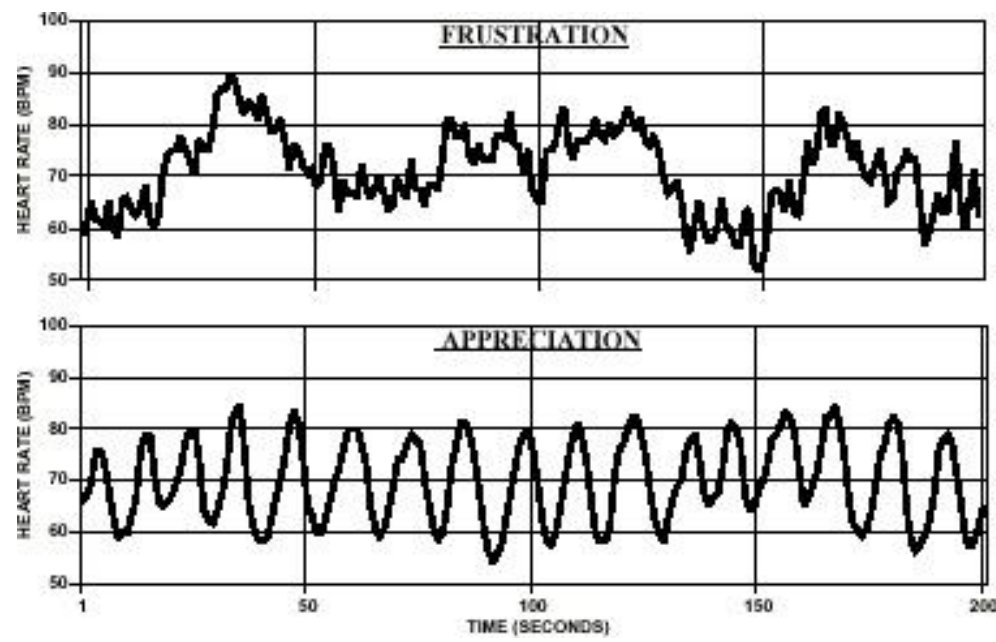

Figure 1. The HRV reading for a state of frustration compared to one for appreciation. (McCraty, Atkinson,

Tomasino \& Bradley, 2009, p.9)

\subsection{Emotional Regulation}

Utilising the knowledge that HRV co-varies with emotion, emotional regulation interventions were designed that combined HRV Biofeedback, resonant breathing and the self-generation of positive emotions (McCraty et al., 1995). This meta-synthesis will review the results of utilising these interventions in the workplace.

\subsection{Psychophysiological coherence.}

The visual representation of the ANS activity through HRV biofeedback opened up possibilities to develop and test techniques using positive emotions to improve HRV coherence. Psychophysiological coherence (McCraty \& Rees, 2009) refers to the state of increased entrainment and synchronization between the heart rhythms and a multiple of other bodily systems such as respiratory, blood pressure and craniosacral rhythms that the intervention creates; it denotes "a global state of optimum performance" (ibid., p.529). In the spectral analysis of the HRV reading, the biofeedback tool will exhibit it as a very narrow high-amplitude peak in the low frequency region of the power spectrum Practise of coherence building techniques strengthens the link between the state of psychological coherence and positive emotion which enables positive emotions to trigger increased coherence and vice versa. It is stipulated that a physiological shift into coherence will facilitate positive emotion. The techniques transform the stress response in the moment it occurs and they lead to a long term benefits of building a new healthier baseline (ibid.) which the system then strives to maintain (Pribram, 1991).

\subsection{ANS}

Both Porges (1994) and Thayer and Lane (2000) have shown the link between the flexibility of the ANS, as represented by HRV, and the regulation of emotional responses. HRV can be seen as an index of the self-regulatory muscle (Segerstrom et al., 2007). Baumeister's research suggests that self-regulation can be increased with practice (Baumeister, Gailliot, DeWall \& Oaten, 2006). This has been demonstrated in research with physical exercise (Oaten \& Cheng 2006a), the management of money (Oaten and Chang, 2007) and study (Oaten \& Cheng, 2006b). Self-regulation built through practice in a specific area extends to benefit unrelated areas (Baumeister et al, 2006).

An increase in HRV is linked to improved ability to adapt to challenges as well as physiological and psychological benefits. Research shows that the practice of techniques, which are based on self-generated positive emotion and HRV biofeedback, can create a re-patterning in the neural architecture so that the new level of coherence becomes the revised baseline (McCraty \& Childre 2010). This is supported by electrophysiological evidence (Bradley et al., 2011). With regular practice, self-regulation of emotions and improved stress responses become increasingly habitual and eventually automatic (McCraty, Barrios-Choplin, Rozman, Atkinson \& Watkins, 1998).

\section{Methods}

\subsection{Overview}


There were four phases to this meta-synthesis. First a search strategy was designed and executed. Then records were screened for quality, next they were appraised and finally synthesised.

\subsection{Search strategy}

A systematic search of electronic databases was undertaken using PsycINFO, PubMed and Business Source Complete. Word searches included: Heart rate variability, HRV, biofeedback, positive emotion, performance, stress, intervention, resonant breathing, and psychological well-being. Included were peer reviewed articles of studies, both quantitative and qualitative, that were workplace based interventions utilising HRV Biofeedback and self-induced positive emotions. Each study was appraised utilising the Critical Appraisal Skills Programme (CASP) (CASP - UK, 2013).

\subsection{The Synthesis Papers}

Nine papers met the inclusion criteria and the quality criteria. Seven studies were conducted in the U.S.A.; one was conducted in Canada and one in Thailand. The size of the experimental groups varied from 18 to 144 with an average of 55. The nature of the populations examined varied, for example, from: 65 police officers, 20 physicians, 100 nurses in the Mayo Clinic, 48 Motorola employees, 44 correctional officers and 144 pastors (table 1). All studies, at a minimum used HRV Biofeedback during the training. Five studies, those which were conducted from 2010 onwards, also benefitted from the use of a personal handheld HRV device for use during practice sessions. 6 studies used physiological measures, all 9 used psychological measures.

Table 1. Study Characteristics.

\begin{tabular}{|c|c|c|c|c|c|c|c|}
\hline & Author \& date & Journal Title & Journal & Participants & $\begin{array}{l}\text { Grp } \\
\text { size }\end{array}$ & Location & Method \\
\hline 1 & McCraty, 2012 & $\begin{array}{l}\text { POLICE STUDY. Resilience Training program reduces physiological and } \\
\text { psychological stress in police officers }\end{array}$ & $\begin{array}{l}\text { Global Advances in } \\
\text { Health \& Medicine }\end{array}$ & $\begin{array}{c}64 \text { sworn police officers and } 1 \text { city } \\
\text { manager }\end{array}$ & 65 & U.S.A & Quant\& Qual \\
\hline 2 & Lemaire, 2011 & $\begin{array}{l}\text { PHYSICIANS STUDY. The effect of a biofeedback -based stress mangement } \\
\text { tool on physician stress: a randomized controlled clinical trial }\end{array}$ & Open Medicine & $\begin{array}{l}\text { Staff physicians practising in an } \\
\text { urban tertiary care centre. }\end{array}$ & 20 & Canada & Quant\& Qual \\
\hline 3 & McCraty, 1998 & $\begin{array}{l}\text { DHEA/CORTISOLSTUDY. The impact of a new emotional self } \\
\text { management program on stress, emotions, heart rate variability, DHEA and } \\
\text { Cortisol }\end{array}$ & $\begin{array}{l}\text { Integrative psy chological } \\
\& \text { Behavioural Science }\end{array}$ & $\begin{array}{l}\text { Healthy working adults recruited } \\
\text { from the local community }\end{array}$ & 30 & U.S.A & Quant \\
\hline 4 & McCraty, 2009 & $\begin{array}{l}\text { CORRECTIONAL OFFICERS STUDY. New Hope for Correctional } \\
\text { Officers: An innovative program for reducing stress and health risks. }\end{array}$ & $\begin{array}{c}\text { Applied } \\
\text { Psychophysiology \& } \\
\text { Biofeedback }\end{array}$ & Correctional officers & 44 & U.S.A & Quant \&Qual \\
\hline 5 & Bedell, 2010 & $\begin{array}{l}\text { PASTORS STUDY. Coherence and health care costs - RCA Actuarial study: } \\
\text { a cost-effectiveness cohort study }\end{array}$ & Alternative Therapies & $\begin{array}{l}\text { Pastors from the Reformed Church in } \\
\text { America. }\end{array}$ & 144 & U.S.A & Quant \\
\hline 6 & $\begin{array}{l}\text { Tatanasiripong, } \\
\quad 2012\end{array}$ & $\begin{array}{l}\text { NURSING STUDENTS STUDY. Biofeedback intervention for stress and } \\
\text { anxiety among nursing students: a randomised controlled trial }\end{array}$ & ISRN Nursing & Female nurses in Thailand & 30 & Thailand & Quant \\
\hline 7 & Britt Pipe, 2012 & $\begin{array}{l}\text { MAYO CLINIC NURSES STUDY. Building personal and professional } \\
\text { resources of Resilience and Agility in the healthcare workplace }\end{array}$ & Stress and Health & $\begin{array}{l}\text { Nurses from haematology/oncology } \\
\text { and clinical managers }\end{array}$ & 100 & U.S.A & Quant \\
\hline 8 & $\begin{array}{l}\text { Barrios-Choplin, } \\
1997\end{array}$ & $\begin{array}{l}\text { MOTOROLA STUDY. An inner quality approach to reducing stress and } \\
\text { improving physical and emotional wellbeing at work }\end{array}$ & Stress Medicine & $\begin{array}{l}\text { Executives, software engineers and } \\
\text { factory workers }\end{array}$ & 48 & U.S.A & Quant \\
\hline 9 & McCraty, 2003 & $\begin{array}{l}\text { HYPERTENSIVE EMPLOYEE STUDY. Impact of a workplace stress } \\
\text { reduction program on blood pressure and emotional health in hypertensive } \\
\text { employees }\end{array}$ & $\begin{array}{c}\text { The Journal of } \\
\text { alternative and } \\
\text { complementary medicine }\end{array}$ & $\begin{array}{l}\text { Hypertensive employees in a global } \\
\text { information technology company }\end{array}$ & 18 & U.S.A & Quant \\
\hline
\end{tabular}

\subsection{Synthesis}

The studies were synthesised using a systematic review methodology (Shaw, 2011). Data extraction forms were created (Malpass et al 2009). Meta-ethnography (Noblit \& Hare 1988) as adapted by Britten et al (2002) was used to synthesis the themes. A table of themes was created (Braun \& Clarke, 2006), then a refutal and reciprocal analysis of themes was conducted, from which a line of argument analysis was derived in order to create third order constructs.

\section{Results}

\subsection{Summary}

The themes are: physiological improvements, reduction in negative affect, increase in positive affect, improved 
cognitive performance and improved organizational performance.

\subsection{Physiological Improvements}

Six out of the nine studies used physiological measures [1,2,3,4,8,9] such as, blood pressure, cholesterol, glucose, DHEA, cortisol and HRV. These physiological measures provide additional information regarding stress and create valuable data when working with groups who tend to under report their stress levels and symptoms [4].

Four of the interventions used blood pressure (BP) measures. In one study aimed specifically at hypertensive employee populations[9], the intervention, conducted over a four week period, showed a significantly significant reduction in systolic BP ( $<<0.05)$, whilst there was also a marked reduction of diastolic BP of $6.3 \mathrm{~mm} \mathrm{Hg}$. A reduction of $3.9 \mathrm{~mm}$ HG in the control group however, rendered it not statistically significant. Three of the 18 participants in the experimental group were able to reduce their antihypertensive medication with their physician's agreement and one of was able to discontinue their medication by the end of the study. The BP reduction achieved compared favourably in magnitude to the results achieved in a meta-analysis of controlled trials on hypertensive drugs therapy of several years duration published in the Lancet (Collins et al, 1990). It was also twice the average BP reduction normally seen with weight loss interventions of $201 \mathrm{bs}$.

In a study conducted at Motorola [8], 28\% (five employees) of the experiment group were classified as hypertensive at the start of the intervention. At the end of the six month program, they were all classified as either normal or high normal. Additional significant reductions were also achieved if readings were taken after using the Freeze-Frame ${ }^{\circledR}$ (HeartMath, 2013). In the study with correctional officers [4], over a ninety day period overall BP showed reductions $(p=<0.001)$ as did both systolic $(p=<0.001)$ and diastolic $(p=<0.01)$. However, there was some refutal data from the physician's study [2] where no statistically significant reduction in BP was recorded. Although it is worth noting that only three of that experiment group of twenty had BP above $140 \mathrm{~mm}$ at the start of the intervention which renders the comparison less valuable.

Cholesterol readings were only taken in one study [4].In this study with correctional officers there was a significant pre-post difference in both total cholesterol LDL and in total cholesterol HDL ratio( $p=<0.001)$. This study also contained the only reference to glucose readings where it achieved a statistically significant reduction $(\mathrm{p}=<0.01)$.

A study[3] using specific techniques of "Cut-Thruß" (HeartMath.com, 2013) and "Heart Lock-In®" (HeartMath.com, 2013) which were designed to eliminate negative thought loops and create sustained positive emotion states recorded a significant reduction of $23 \%$ in cortisol and a $100 \%$ increase in DHEA over the one month period of the study. These results exceed those that can normally be achieved by any medication regime. The only other study that recorded a cortisol and DHEA measure [4] did not show a statistically significant change in either cortisol or DHEA. The interventions differed however, as study 3 specifically focused on restructuring techniques designed to change deep routed patterns, as the intervention in study [4] was more generalised, a simple comparison is less appropriate.

Whilst all studies used HRV Biofeedback as a core aspect of the training intervention, five studies recorded the change in the participants' HRV over the intervention period [1-4,8]. In the studies with correctional officers and Motorola employees $[4,8]$, there was a reduction in resting autonomic activity $(\mathrm{p}=<0.05)$, which suggests a shift in baseline emotional state to one of decreased tension and anxiety.

Where twenty four hour HRV readings were recorded [3], the autonomic function analysis showed that 20 out of the 25 participants had improvements in their HRV at times that coincided with the log book entries which showed their use of the techniques at that respective time. The studies in this meta-synthesis show that regular practice of these self-regulation techniques can increase HRV, which has been shown to improve autonomic health (McCraty et al., 1998).

\subsection{Reducing negative affect - overview}

The statistically significant reduction of negative affect was a strong theme that was prominent in all nine studies. The police study [1] showed a reduction in distress, negative emotions, depression, fatigue and sleeplessness. The physician study [2] showed that 15 of the 20 physicians in the experiment group had a reduction in stress score at day 28 relative to day 0 . Additional adherence data showed that $100 \%$ of those with good adherence to the intervention had a decrease in their stress score. This adherence data highlights that without regular practise, the potential of these interventions will not be realised. In the study of hypertensive employees [3] there was a reduction in guilt, hostility, burnout, over care, anxiety and stress effects. The study of correctional officers [4] showed a reduction in anger and fatigue. Also using the Jenkins Activity Survey it showed significant reductions in the global scale that measure Type A behaviour such as speed and impatience. The success of studies in high stress environments like the police indicates that they are likely to be successful in other high stress occupations [4].

The pastors' study [5] showed a statistically significant reduction in total stress, work stress, physical symptoms of 
stress and a reduction in lack of support. The nursing student study [6] showed only a slight increase in stress at a time when a significant increase in stress was anticipated and was witnessed in the control group. The nurses in the Mayo clinic [7] had significant reductions in fatigue, anxiety, depression, anger management, resentfulness and stress symptoms. The Motorola study [8] showed a statistically significant reduction in nervousness, and the physical symptoms of stress among the white collar workers, and a reduction in tension and anxiety among the blue collar workers.

\subsection{The reduction of Depression and Anxiety Symptoms.}

Three studies noted a reduction in depression $[1,7,9]$. This has the potential to impact health care costs in business as depression is linked to significant productivity loss (Steward, Ricci, Chee, Hahn \& Morganstein, 2003). Two studies [6,9] used specific measures for anxiety. The study of hypertensive employees [9] used a brief symptoms inventory which showed a reduction in symptoms of depression and phobic anxiety $(\mathrm{p}=<0.05)$. A similar $\mathrm{p}$ value was achieved in the reduction of stress symptoms and the overall severity of psychological distress. The study of nursing student [6] used the perceived stress scale and showed a reduction of total stress, work stress, physical symptoms of stress and a reduction in lack of social support all with a $\mathrm{p}$ value of $<0.05$. This study also used the state anxiety scale which showed a significant decrease.

Stress results from how an individual perceives and responds to an event. These interventions revised their interpretative style $[3,8]$ by using positive emotion to interrupt their habitual perceptual tendencies and their resultant physiological consequences. These negative thought loops and their impact on the ANS were reprogrammed at a neural circuitry level as a result of a redirection of their emotional state (McCraty, 2006). With practice, this re-pattern can become the new baseline [1]. The police study [1] showed that it was an effective way to deal with chronic stress. With regular practice, the new emotional regulation became familiar and in time automatic. This was reported as an increased insight into their own psychological well-being and an increased ability to manage their moods and more confidence that they could manage their stress reaction [1]. The Police study analysed scenario simulations that showed their heart rates to remain elevated for an average of 60 minutes after a stressful event such as guns raised in a domestic violence incident. Using 24 hour HRV monitors they could evidence a police man trained in the self-regulation techniques having a heart rate increase to 180 beats per minute (BPM) when guns were raised and its return to normal of $80 \mathrm{BPM}$ within 10 minutes, a reduction of $83 \%$ compared to his peers who were not trained in this intervention.

\subsection{Increase in positive affect}

A statistically significant increase in positive affect was a strong theme in eight of the nine papers [1-5,7-9]. The one exception [6] focused exclusively on measures of stress reduction and did not explicitly collect data on positive affect.

There were a variety of dimensions of positive affect: caring, vigour, gratitude, positive outlook, motivation, calmness, contentment, peacefulness and vitality. The average level of change was $p=<0.05$. In the oncology unit in the Mayo Clinic [7] where there was a comprehensive, leader lead, total organisation implementation that built the principles and practices into their culture, the results were stronger. They showed a change from base line to seven months post intervention of $p=<0.001$ on each of the personal indicators of positive outlook, gratitude, motivation and calmness.

The interventions encompass the positive aspects of the relaxation response but are markedly different as they also increase mental clarity and cognitive performance [9]. The psychophysiological coherence mode is associated with increased PSNS activity as in the relaxation response; however the fact the system is oscillating at its resonant frequency, creates a distinctly different physiological state of harmony in the nervous system and heart-brain dynamics, characterised by alertness which is conducive to optimal performance unlike the laid back nature of the state of relaxation (McCraty et al., 2009).

\subsection{Improvement in organisational performance}

Six out of the nine studies reported improvements in organisational performance [1,3-5,7,9]. The pastors' study [5] was specifically designed as an actuarial study to analyse the impact the intervention had on health care costs. It recorded a significant improvement with adjusted annual medical costs for the intervention group being minus $3.8 \%$ while the control group were plus $9 \%$. Pharmacy costs were also lower for the intervention group at minus $7.95 \%$ compared to plus $13.3 \%$ for the control group. The correctional officer's study [4] also showed that at the completion of the intervention, $43 \%$ of the experimental group had reduced enough risk factors to place them in a lower category of project cost status, which their analysis showed would reduce their health care costs by $18 \%$.

Two studies $[7,8]$ showed that organizational quality was improved as indicated by statistically significant increases in the following factors: communication effectiveness, time pressure, manager support, value of contribution and workplace satisfaction. Two studies [1,3] highlighted the power of improved cortical function that resulted from the intervention. Decision making whilst in a stress response will be impacted by an amygdala hijack (Goleman \& 
Sutherland, 1996) that bypasses the rational reasoning of the neocortex (Le Doux, 1998). This can have seriously detrimental impacts on organisational performance as highlighted in the police study [1] where decisions made in the moment can literally mean life or death.

The nursing student's study [6] showed how it helped them make challenging transitions successfully. Increased self-regulation and physiological coherence resultant from the interventions resulted in significant cost savings [5].

\subsection{Additional insights from qualitative study}

The correctional officers' study [4] conducted post intervention telephone interviews with twenty of the participants. This created useful insight into continued application of the learning. Nineteen (95\%) said they found the tools "useful". Seventeen $(85 \%)$ reported using the tools at least three times a week, while eleven $(65 \%)$ said they used them daily. This is also mirrored by reference in the physicians' study [2] where a post intervention qualitative study (unpublished data) reported that almost all of them intended to continue using the tools because of the beneficial effect on their workplace stress.

\section{Discussion}

Fredrickson and Kok reviewed the efficacy of self-generated positive emotions to improve vagal tone, as measured by HRV (Kok et al., 2013). Their intervention was a loving kindness meditation which did result in improved vagal tone. This meta-analysis shows an alternative intervention which may be more readily adopted in business environments than loving kindness meditation as it may be perceived as easier to learn and less ethereal. The nature of fast paced business environments means that for many employees mindfulness is not a practice they feel they can adopt. The option of moment by moment feedback during brief 5 minute training sessions may lead to higher adoption levels.

As previously discussed, the increased self-regulation optimises the performance of the existing employee base. In a time of economic challenges it enables an organisation to be more effective utilising its existing resources. The resultant psycho physiological coherence creates an ideal foundation on which higher states of creativity and flow are more likely to occur.

These studies evidence how positive emotions have a profound positive impact on the ANS. It is a highly tangible and credible way to introduce positive emotions into the workplace. Once leaders and employees have reached a strong personal conviction of how they improve their well-being through these interventions they are likely to be more receptive to further work regarding positive emotions in the workplace in order to reap the benefits highlighted in the broaden and build theory (Fredrickson, 1998) such as increased resources and creativity. This would also create a culture in which the principles of appreciative inquiry (Cooperrrider, 1987) are much more likely to be understood and adopted.

The emphasis on appreciation as a positive emotion in these interventions has the potential to mirror the benefits of many gratitude exercises, such as 3 good things (Seligman, Parks \& Steen, 2004) currently popular in positive psychology. The practice involved in the intervention creates a platform for focused attention and momentary detachment that has some similarities with mindfulness, yet may be a more accessible practice for some. These interventions could create an excellent experiential foundation for learning to shift from the learnt helplessness of pessimism towards agency thinking and optimism (Seligman, 2011).

In 2013, an iPhone/IPad application Inner balance ${ }^{\mathrm{TM}}$ (HeartMath, 2013) was released that records HRV, using an ear sensor, and illustrates it in bright graphical forms. Its benefit is a significant reduction on the price traditionally charged for this type of technology. This now makes this type of intervention more affordable in business settings and all the more attractive to a generation of digital natives. It will also make research more affordable and could streamline the collection of adherence data.

\section{Conclusion}

The effects of these workplace self-regulation interventions are physiological, psychological and organisational. At the physiological level they can have a beneficial impact on the following factors: blood pressure, cholesterol, glucose, DHEA, cortisol and HRV. At a psychological level they decrease negative affect and increase positive affect. They impacted organisational performance through improvement in: organizational quality, cognitive performance, ability to manage stressful transitions and reduced costs.

\section{References}

Baumeister, R. F., Gailliot, M., DeWall, C. N., \& Oaten, M. (2006). Self-Regulation and Personality: How Interventions Increase Regulatory Success, and How Depletion Moderates the Effects of Traits on Behavior. Journal of personality, 74(6), 1773-1802. http://dx.doi.org/ 10.1111/j.1467-6494.2006.00428.x 
Braun, V., \& Clarke, V. (2006). Using thematic analysis in psychology. Qualitative research in psychology, 3(2), 77-101. http://dx.doi.org/ 10.1191/1478088706qp063oa

Britten, N., Campbell, R., Pope, C., Donovan, J., Morgan, M., \& Pill, R. (2002). Using meta ethnography to synthesise qualitative research: a worked example. Journal of Health Services Research \& Policy, 7(4), 209-215. http://dx.doi.org/ 10.1258/135581902320432732

Casp, 2013. Retrieved on the 1st April 2013 from http://www.casp-uk.net/wp-content/uploads/2011/11/CASP-Qualitative-Research-Checklist-31.05.13.pdf

Chida, Y., \& Steptoe, A. (2008). Positive psychological well-being and mortality: a quantitative review of prospective observational studies. Psychosomatic Medicine, 70(7), 741-756. http://dx.doi.org/10.1097/psy.0b013e31818105ba.

Collins, R., Peto, R., MacMahon, S., Godwin, J., Qizilbash, N., Hebert, P., ... \& Fiebach, N. H. (1990). Blood pressure, stroke, and coronary heart disease: part 2, short-term reductions in blood pressure: overview of randomised drug trials in their epidemiological Eisenberg, N., Carlo, G., \& Murphy, B. (1995). Prosocial development in late adolescence: a longitudinal study. Child development, 66(4), 1179-1197.

Cooperrider, D. L., \& Srivastva, S. (1987). Appreciative inquiry in organizational life. Research in organizational change and development, 1(1), 129-169.

El-Sheikh, M., \& Harger, J. (2001). Appraisals of marital conflict and children's adjustment, health, and physiological reactivity. Developmental Psychology, 37(6), 875. HTTP://DX.DOI.ORG/ 10.1037/0012-1649.37.6.875

Fredrickson, B. L. (1998). What good are positive emotions?Review of general psychology, 2(3), 300. http://dx.doi.org/ 10.1037/0003-066x.56.3.218

Fredrickson, B. L., Mancuso, R. A., Branigan, C., \& Tugade, M. M. (2000). The undoing effect of positive emotions. Motivation and emotion, 24(4), 237-258. http://dx.doi.org/ 10.1023/1010796329158

Goleman, D., \& Sutherland, S. (1996). Emotional Intelligence: Why it can matter more than IQ. Nature, 379(6560), 34-34.

HeartMath. (2013). Retrieved from www.HeartMath.org on $29^{\text {th }}$ July 2013.

Kok, B. E., Coffey, K. A., Cohn, M. A., Catalino, L. I., Vacharkulksemsuk, T., Algoe, S. B., ... \& Fredrickson, B. L. (2013). How Positive Emotions Build Physical Health Perceived Positive Social Connections Account for the Upward Spiral Between Positive Emotions and Vagal Tone. Psychological science. http://dx.doi.org/10.1177/0956797612470827

Kubzansky, L. D., \& Thurston, R. C. (2007). Emotional vitality and incident coronary heart disease: benefits of healthy psychological functioning. Archives of General Psychiatry, 64(12), 1393. http://dx.doi.org/10.1001/archpsyc.64.12.1393.

LeDoux, J. (1998). The emotional brain: The mysterious underpinnings of emotional life. SimonandSchuster. com.

Malpass, A., Shaw, A., Sharp, D., Walter, F., Feder, G., Ridd, M., \& Kessler, D. (2009). "Medication career” or “Moral career"? The two sides of managing antidepressants: A meta-ethnography of patients' experience of antidepressants. Social science \& medicine, 68(1), 154-168. http://dx.doi.org/ 10.1016/j.socscimed.2008.09.068

McCraty, R., \& Childre, D. (2010). Coherence: bridging personal, social, and global health. Altern Ther Health Med, 16(4), 10-24.

McCraty, R., \& Rees, R. A. (2009). The central role of the heart in generating and sustaining positive emotions. Oxford handbook of positive psychology, 527-536.

McCraty, R., Atkinson, M., Tiller, W. A., Rein, G., \& Watkins, A. D. (1995). The effects of emotions on short-term power spectrum analysis of heart rate variability. The American journal of cardiology, 76(14), 1089-1093. http://dx.doi.org/ 0.1016/s0002-9149(99)80309-9

McCraty, R., Atkinson, M., Tomasino, D., \& Bradley, R. T. (2009). The coherent heart: Heart-brain interactions, psychophysiological coherence, and the emergence of system-wide order. Integral Review, 5(2), 10-115.

McCraty, R., Barrios-Choplin, B., Rozman, D., Atkinson, M., \& Watkins, A. D. (1998). The impact of a new emotional self-management program on stress, emotions, heart rate variability, DHEA and cortisol. Integrative Physiological and Behavioral Science, 33(2), 151-170. http://dx.doi.org/ 10.1007/bf02688660

Noblit, G. W., \& Hare, R. D. (1988). Meta-ethnography: Synthesizing qualitative studies. Sage. 
Oaten, M., \& Cheng, K. (2006a). Longitudinal gains in self - regulation from regular physical exercise. British Journal of Health Psychology, 11(4), 717-733.

Oaten, M., \& Cheng, K. (2006b). Improved self-control: The benefits of a regular program of academic study. Basic and Applied Social Psychology, 28(1), 1-16. http://dx.doi.org/ 10.1207/s15324834basp2801

Oaten, M., \& Cheng, K. (2007). Improvements in self-control from financial monitoring. Journal of Economic Psychology, 28(4), 487-501. http://dx.doi.org/ 10.1016/j.joep.2006.11.003

Ostir, G. V., Markides, K. S., Peek, M. K., \& Goodwin, J. S. (2001). The association between emotional well-being and the incidence of stroke in older adults. Psychosomatic medicine, 63(2), 210-215.

Oveis, C., Cohen, A. B., Gruber, J., Shiota, M. N., Haidt, J., \& Keltner, D. (2009). Resting respiratory sinus arrhythmia is associated with tonic positive emotionality. Emotion, 9(2), 265. http://dx.doi.org/ 10.1037/a0015383

Porges, S. W., Doussard - Roosevelt, J. A., \& Maiti, A. K. (1994). Vagal tone and the physiological regulation of emotion. Monographs of the Society for Research in Child Development, 59(2-3), 167-186. http://dx.doi.org/ 10.1111/j.1540-5834.1994.tb01283.x

Pribram, K. H. (1991). Brain and perception: Holonomy and structure in figural processing. Psychology Press.

Segerstrom, S. C., \& Nes, L. S. (2007). Heart rate variability reflects self-regulatory strength, effort, and fatigue. Psychological science, 18(3), 275-281. http://dx.doi.org/ 10.1111/j.1467-9280.2007.01888.x

Seligman, M. E. (2011). Learned optimism: How to change your mind and your life. Random House Digital, Inc.

Seligman, M. E., Parks, A. C., \& Steen, T. (2004). A balanced psychology and a full life. Philosophical Transactions-Royal Society of London Series B Biological Sciences, 1379-1382.

Stewart, W. F., Ricci, J. A., Chee, E., Hahn, S. R., \& Morganstein, D. (2003). Cost of lost productive work time among US workers with depression. JAMA: the journal of the American Medical Association, 289(23), 3135-3144. http://dx.doi.org/ 10.1001/jama.289.23.3135

Thayer, J. F., \& Lane, R. D. (2000). A model of neurovisceral integration in emotion regulation and dysregulation. Journal of affective disorders, 61(3), 201-216. http://dx.doi.org/ 10.1016/s0165-0327(00)00338-4

\section{(cc) $\mathrm{BY}$}

This work is licensed under a Creative Commons Attribution 3.0 License. 